\title{
Editorial
}

\section{Impact of COVID-19 Pandemic on Health Care Providers- Bangladesh Perspective}

The novel human corona virus disease COVID-19 has become the fifth documented pandemic since the $1918 \mathrm{flu}$ pandemic. COVID-19 is first reported in Wuhan, China and subsequently spread worldwide. The corona virus was officially named as severe acute respiratory symptoms corona virus 2 (SARS-COV-2) by the International Committee on Taxonomy of virus based on phylogenic analysis. SARS-COV-2 is believed to be a spillover of an animal coronavirus and later adapted the ability of human to human transmission. Because the virus is highly contagious it rapidly spreads and continually evolves in the human population. Human corona virus usually causes mild upper respiratory diseases. However, in the past two decades two corona virus transmitted from animal, SARSCOV and MERS-COV has caused severe pneumonia and death in human. In addition since late December, 2019, the COVID-19 pandemic has spread globally and consequently results in 416062 death worldwide and May 31, 2021. Due to the high sequence homology with a coronavirus isolated from bats, SARS-COV-2 is considered a zoonotic origin coronavirus. Undoubtedly, SARS-COV-2 has become the fifth human coronavirus and it is possible that this virus will continually circulate in the human population in the future. Because specific antiviral treatment and vaccine are still under developmental testing, using masks, quarantine and social distancing are encouraged to prevent viral spread. Nonetheless since the virus keeps mutating and evolving during the pandemic, study on viral pathogenicity, treatment and prophylactic vaccine should closely consider the genotypic characteristics of the virus. Vaccination is one of the tools to fight COVID 19. Our government has planned to vaccinate health care professionals and general population above the age of 40 years at free of cost. Our total population is 156,118464 , first dose taken by 5,819,900 (3.7\%), Second dose taken by $3,496186(2.2 \%)$. FDA has approved vaccination in the USA from the age of 12years from 13th May. As lock down is difficult to maintain in our country and as more people are from low income group massive vaccination can be considered here to fight COVID-19. Some times it may not be possible to get same vaccine as first and second dose.
Scientists are now working on matching of vaccines from different sources as first and second dose and they are hopeful of it.

Though our patients are taking help from our doctors over telemedicine, some times they need for intervention and have to come in contact with doctors. We can't refuse this and doctors are providing helath care services taking necessary precautions and health care procedure even if the patient is COVID positive. Usually $79 \%$ of patients stay at home and get treatment over phone. The MetaAnalysis revealed that approximately one-third of patients with COVID-19 needs ICU and more than thirty percent patient within ICU are dying. Government hospitasl have ICU which is $22 \%$ percent of total number of ICU in Bangladesh and the number is 223 and the ratio of general bed to ICU is 219:1, which should be 10:1 for standard health care service during pandemic. In Bangladesh only 3.05 doctors and 1.07 nurses serve every 10000 people on average which is insufficient for pandemic situation. Many doctors got infected and some died making doctors mortality rate highest in the world. Honorable Prime Minister declared incentive package of USD 12.13 billion from which Ministry of Health purchased ventilators and added ICU, HDU and isolation wards in our government hospitals. Some of the Government hospitals have been designated for COVID patients as Mugda General Hospital, some are treating both COVID and Non-COVID patients like Shaheed Suhrawardy Medical College Hospital. In the hospital where there is both COVID and Non- COVID patients chance of spread of corona virus is more among patients, attendant and health care professionals. Sometimes non-COVID illness may present with features of COVID patients and we can't ignore them and are admiting them in isolation ward in extra beds even though there is shortage of bed. Otherwise patients may die on the road during transfer to another hospital mutilating our image as front liner. Corporate private hospitals are treating COVID patients as well and small private hospitals without structure to treat COVID patients are treating non-COVID patient decreasing load on the COVID patient treating hospitals. Isolation wards added 


\begin{tabular}{llcc}
\multicolumn{4}{c}{ Reported tests per 1,000 people in South Asian countries } \\
Rank & Country & Test per 1,000 & Percent \\
\hline 1 & Maldives & 69.4 & 6.9 \\
2 & Bhutan & 30.3 & 3.0 \\
3 & India & 4,9 & 0.5 \\
4 & Pakistan & 4,8 & 0.5 \\
5 & Nepal & 4.6 & 0.5 \\
6 & Sri Lanka & 4.2 & 0.4 \\
7 & Bangladesh & 3.4 & 0.3 \\
S & Afghanistan & 1,6 & 0,2 \\
\hline
\end{tabular}

Sources: Johns Hopkins Corona Resource Center, the World Bank, and Our World.

all district and upozilla hospitals to treat COVID patients without complications. We have to test more people to detect carrier and isolate them. Bangladesh is below in the list of countries in South East Asia testing people for COVID- 19 .
Still we can fight COVID 19 together with day-to-day update from our experts working under Ministry of Health to get a COVID controlled society by mass vaccination and maintaining health care instruction.

[J Shaheed Suhrawardy Med Coll 2020; 12(2): 61-62] DOI: https://doi.org/10.3329/jssmc.v12i2.56882

\section{Sami Ahmed ${ }^{1}$, Md. Mustafizur Rahman ${ }^{2}$}

1. Associate Professor of Surgery, Shaheed Suhrawardy Medical College, Dhaka, Mobile: 01711600447, E-mail: dr.sami39@gmail.com

2. Professor \& Head, Department of Surgery, Shaheed Suhrawardy Medical College, Dhaka.

\section{References:}

1. Coronavirus disease (COVID-19) update. World Health Organization 2020.

2. COVID- 19 situation report 13. World Health Organization 2020 .

3. K. Iserok, Health care ethics during a pandemic, West J Emerg. Med, 21 (2020) 